\title{
10 \\ Inspiring Writing in the Sciences: An Undergraduate Electronic Journal Project
}

\author{
Peggy Pritchard \& Dan Thomas \\ University of Guelph
}

Most faculty will agree that students must learn to write well (Emerson, MacKay, MacKay, \& Funnell, 2006), and in the sciences, a variety of approaches have been taken. In the College of Physical and Engineering Science at the University of Guelph, we have developed a way of embedding research, writing, and analytical skills into an introductory Nanoscience course that gives students the true-to-life experience of writing for publication, ignites their imaginations, and inspires them to do their best. Following the process of scholarly publication, students become researchers, authors, and reviewers for an electronic journal. Through appropriately timed workshops and tutorials, they receive support and feedback. Rubrics for the assessment of the students' performances as authors and peer reviewers provide them with more insight into what constitutes work that falls below expectations, or meets or exceeds them. These rubrics also enable faculty to evaluate student contributions efficiently and fairly. In this essay, we showcase a suite of pedagogical tools that includes learning activities, open access software and assessment rubrics, and share our experiences of a faculty-librarian collaboration.

\section{The Dilemma}

$I^{\prime \prime}$ n 2008 the College of Physical and Engineering Science at the University of Guelph introduced a new, interdisciplinary major. The first of its kind in Canada, the B.Sc. Nanoscience program focuses on an integrated approach to the investigation of nanoscale materials (a "nano" is one billionth of a metre): the study of the properties and synthesis of matter designed in dimensions from 1 to 100 nanometers (by comparison, a red blood cell is approximately 8,000 nanometers in diameter). Such materials possess novel chemical reactivity and physical properties that can lead to important new devices. By drawing upon the expertise of faculty from the pure and applied sci- 
ences, the curriculum integrates complementary, but historically siloed, sciences. In addition, the program conforms to the University's and College's broader educational mission of supporting the development of the whole student, including his or her facility with written communication. ${ }^{1}$

Research on writing reveals that "there is a specific deficiency in the writing skills of high school and college graduates, especially among engineering and science students" (National Commission on Writing in America's Schools and Colleges, 2003; Stormshak, 2004, p. 2816). Our own experience has taught us that beginning science students are poor writers. Many believe that written communication is not an essential part of their development or their future work, and that we, as instructors and mentors, have not helped them understand its importance. Our solution was to address these issues early in students' academic career by embedding scientific writing and the following associated skills into the introductory course in Nanoscience (NANO*1000):

- definition of a scientific problem;

- critical thinking;

- strategic literature searching, critical reading, analysis, and synthesis;

- communication of ideas, engaging writing, and avoiding plagiarism through proper citing and referencing; and

- critical review of peers' writing, and providing written feedback that is specific, constructive and respectful.

When course developers want to be intentional about supporting writing and associated skills, important questions present themselves: How can we make writing meaningful for our students, rather than just one more assignment to complete as quickly as possible, check off their "to do list," then promptly forget? What kind of activity can we develop that will engage our students and motivate them to do their best? How can we support their efforts as beginning writers, provide useful, timely feedback that they can apply immediately to improve their performance, and give them an early taste of success?

\section{The Electronic Journal Project}

Our answer to these questions was to have our students follow the process of scholarly publication by becoming researchers, authors, and reviewers for an electronic journal we created specifically for this course. The possibility of being published by the end of their first year of undergraduate study was highly motivating for these competitive, high-achieving students, many of whom had been top performers in high school.

We provided our aspiring authors and peer reviewers with the rubrics that would be used to assess their performances. Our expectations were clearly articulated in language that described beginning, average, and above average performances. In addition, we developed customized, skill-development workshops and tutorials to support their learning efforts and increase their opportunity for success. These were woven into the curriculum and timed to coincide with their need for support. Thus, through these three aspects of our writing-in-the-sciences project - electronic journal, assessment rubrics, and "just-in-time" support workshops - we were able to provide first-year, first-semester students with a trueto-life experience of the scientific communication process that was both challenging and supportive.

\section{The electronic journal}

The central aspect of this project is our electronic journal. Da Vinci's Notebook was created using free software called Open Journal Systems (OJS): http:// pkp.sfu.ca/ojs-journals. Developed by the Public Knowledge Project (http://pkp.sfu.ca/about), this platform was the obvious choice for the course since the University of Guelph's Library has been supporting open access publishing for close to a decade and is host to almost a dozen scholarly, OJS journals. OJS

\footnotetext{
${ }^{1}$ The institution's learning objectives are available online at www.uoguelph.ca/registrar/calendars/ undergraduate/current/c02/c02learningobjectives.shtml
} 
is an easy-to-use tool for managing the flow of documents between student authors, peer reviewers, and course instructors, and provides full, online functionality, including the crucial double-blind peer review. The software keeps track of manuscript versions; tracks the progress of reviewers and authors; includes customizable templates for all correspondence; and manages all stages of manuscript preparation. Even the tasks of copyediting, layout, and proofreading are folded into the software's architecture to create a relatively seamless production process.

The development process was led by the College's primary library contact, Peggy Pritchard, who also acts as the journal's Editor-in-Chief. The current editors and scientific advisory board members are subject specialists from the College of Physical and Engineering Science, and technical support is provided by the Head of the Library's Research Enterprise, and Scholarly Communications team.

\section{Customized, "just-in-time" workshops and tutorials}

Three skill-building workshops tailored to the writing assignment and timed for optimal support were conducted during the semester. Before students began their preliminary investigations of potential topics for their papers, a faculty member from the Department of Physics led a session on the critical reading of scientific papers. Using a recently-published article on nanochemistry that was one of the students' required readings, he outlined the "anatomy" of a journal article and demonstrated three approaches: a five-minute review, thirty-minute review, and one- to two-hour review. Students began to feel less anxious about the reading requirements once they understood that time constraints are a reality for all scientists, as well as students.

During this real-time lesson in "scientist reading science," the physicist admitted that he did not understand all of the chemistry in the article. This provided considerable encouragement to the students. They themselves were struggling with the basics and felt overwhelmed; it was both inspiring and instructive to hear a respected scientist admit to being puzzled, then listen to him summarize what he did understand, describe his assumptions about what he did not understand, and draw reasonable conclusions from an article that was outside his area of expertise. The students began to believe that they, too, could develop comparable ability, given time and practice.

After completing the next steps in the process - narrowing their topics and having them approved - our students were ready to conduct their research. At this point, a workshop on strategic literature searching using tools available both through the web and the University of Guelph's Library portal was presented by one of the authors. Examining the strengths and drawbacks of web-based searching and discovering the enhanced access they have to the scientific literature as members of the University community gave students techniques to be more focused and efficient. They quickly understood that the approach to any one database is transferable to others, and that all work of this type requires the skills of critical reading, analysis, and synthesis.

These skills were further emphasized during the peer review workshop that was offered just prior to assigning student reviewers to the submitted manuscripts. Developed in consultation with the University's learning and writing specialists, the session covered the key aspects of the peer review process: it offered a critique exercise to help students develop familiarity with the assessment rubrics and gave them a chance to discuss how the rubrics could inform their approach to the reviews they were to perform. Once they learned that the rubrics provided the structure for critically reading their assigned manuscripts, and the criteria for assessing the content and presentation of ideas, they approached their tasks with confidence. As a result, their reviews provided specific, constructive, and timely feedback to their peers.

\section{Assessment rubrics}

As with most rubrics, the two we developed for NANO*1000 clearly define what constitutes work that is below expectations or meets, or exceeds them (Pritchard, 2010). Helpful in guiding the students in their own writing, they also provided support for reviewing their peers' papers. Having an organized list of criteria by which their work would be assessed was 
new for most of the students, but the clear descriptions of the performance indicators reassured them that the grading would not be a purely subjective matter. Rather, they reinforced the understanding of scientific approaches to knowledge-making as an enterprise integrating logical, objective measures of performance with empirical observation and quantitative expression of results (North, 1987).

The same held true for the instructors who marked the students' papers and peer reviews. Though each had a practical sense of how to judge student performance based on years of university teaching experience, they were all encouraged by the development of the rubrics to be more explicit in articulating their expectations for the assignments and more consistent in assessing all the work the students submitted.

The rubrics also enabled the instructors and peer reviewers to provide the student authors with formative feedback on the original manuscript they submitted to the journal, without having to assign marks. Instead, the rubrics summarized the key points of the authors' initial performances and provided them an opportunity to improve their writing in light of the reviewers' comments and suggestions. They were also invited to consult with the writing specialists in the University's Learning Commons before resubmitting their final, edited manuscripts. Knowing that they had multiple chances to improve their papers was very reassuring to our first-year authors, and removed some of the anxiety about the project.

\section{Timelines}

In our first offering of $\mathrm{NANO}^{*} 1000$, the electronic journal project was introduced in the second half of the semester and occupied much of our students' time. The process required them to do several things in a compressed period: define their own topics and have them approved by a course instructor (or choose a topic from an approved list); research, write, and submit their manuscripts to the online journal; participate in the double-blind, peer review process; edit their own papers in response to the reviews; and resubmit their edited manuscripts to the journal. It was these edited manuscripts that the course instructors assessed for grades. In this final review, the instructors also decided which, if any, of the manuscripts were worthy of publication. In the following semester, the successful manuscripts were copyedited and published.

\section{Moving Forward}

Entering the second iteration of NANO*1000 provided the opportunity to reflect upon last year's experience. We realized that the supporting elements of the electronic journal project could be significantly enhanced by tightening their organization. The project was introduced earlier in the semester and the workshops and deadlines spread more purposefully throughout the semester. We added some shorter writing assignments that gave our students additional opportunities to practice their writing and to respond to critical feedback. Because of the interest attracted by the electronic journal among our colleagues at the University, its scope was broadened and the title changed from Nanoscience B.Sc. Journal to da Vinci's Notebook. It is now available for use in any undergraduate course in the College.

The scope of da Vinci's Notebook makes it appropriate for use only in undergraduate science programs at the University of Guelph, but the project itself, with its suite of pedagogical tools, can easily be adapted for use in other disciplines and at other institutions. The flexibility of OJS makes it possible to create any number of electronic journals, on any subject, and for any audience. Workshops to support student learning can be developed by instructors, either independently or in consultation with learning, writing, information and subject specialists on their own campuses. Similarly, rubrics can be customized to reflect the learning objectives of the course and the expectations of the instructors.

Our writing-in-the-sciences project continues to provide our first-year Nanoscience students with a unique, multifaceted writing experience, and to showcase the best examples of the class's work through publication in a peer-reviewed electronic journal. At the end of the fall semester of this second academic year, all students completing the course re- 
ceived a final grade that incorporated an assessment of their writing performance. Further, those students whose work was selected for publication are working individually with the University's science writing specialist in the winter semester to develop their writing skills further and improve their manuscripts prior to publication.

The goal of introducing this electronic journal project into the introductory course of the University of Guelph's undergraduate program in Nanoscience was twofold: to strengthen student engagement and enhance student literacy. The former is particularly important for first-year students, and the latter is uniquely important for science students. After its first year of being offered, the effort has resulted in observable improvements in both areas.

\section{Acknowledgements}

This project would not have been possible without the support and assistance of our many University of Guelph colleagues whose special expertise complemented the subject knowledge of the course instructors Dan Thomas and Detong Jiang; and the information research/management expertise of the College's learning and curriculum support librarian, Peggy Pritchard. We wish to acknowledge the following people, in particular:

College of Physical and Engineering Sciences. Tony Vannelli (Dean), Paul Rowntree (Chemistry), and John Dutcher (Physics).

Library/Learning Commons. Wayne Johnston (Head, Research Enterprise and Scholarly Communications), Barbara Christian (Manager, Writing Services), Elizabeth Murison (former Science Writing Specialist), Margaret Hundleby (Science Writing Consultant), and Dale Lackeyram (Science Learning Specialist).

Teaching Support Services. Peter Wolf (Director), Mary Wilson (Curriculum Development Associate), and the other instructors of TSS's 2008 Course
Redesign Institute.

Office of the Associate V.P. (Academic). Nancy Schmidt (Director, Learning and Pedagogy Initiatives).

\section{References}

Emerson, L., MacKay, B.R., MacKay, M.B, \& Funnell, K.A. (2006). A team of equals: Teaching writing in the sciences. Educational Action Research, 14(1), 65-81.

National Commission on Writing in America's Schools and Colleges. (2003). The neglected $R$ : The need for a writing revolution. New York, NY: College Entrance Examination Board, April Report.

North, S.M. (1987). The making of knowledge in composition. Upper Montclair, N.J.: Boynton.

Pritchard, P.A. (2010). The embedded science librarian: Partner in curriculum design and delivery. Journal of Library Administration, 50, 373-396.

Stormshak, F. (2004). Impact of modern technology on graduate education in animal sciences. Journal of Animal Science, 82, 2815-17.

\section{Biographies}

Peggy Pritchard has been supporting student learning and skill development since her graduation from McGill University in 1989 (M.L.I.S). Editor and co-author of a CIHR-funded mentoring manual for aspiring female scientists (2006, Elsevier Academic Press), she has been twice recognized for excellence in teaching (2002 Faculty of Health Sciences Teaching Award, Queen's University; 2009 Academic Librarianship Award, University of Guelph Faculty Association). She works closely with faculty colleagues in the College of Physical and Engineering Science to develop and deliver innovative curricula to under- 
graduate science students.

Dan Thomas completed his undergraduate degree at the University of Alberta, a Ph.D. at the University of Toronto, and post-doctoral work at the University of Washington in Seattle. Since 1989, he has been a member of the Department of Chemistry at the University of Guelph and has recently served as Associate Dean Academic in the College of Physical and Engineering Science. He is pursuing research in both Nanoscience and science education and is helping to found the University of Guelph's new "Institute for Science and Engineering Education Research" (iSEER). 